\title{
DEZ PONTOS DE CONFLUÊNCIA SOBRE CAPITAL INTELECTUAL: UMA INVESTIGAÇÃO A PARTIR DO CONTEXTO DE DUAS MONTADORAS MULTINACIONAIS DE CAXIAS DO SUL
}

\author{
Zolimar Vargas ${ }^{1}$ \\ Vilmar Alves Pereira²
}

\begin{abstract}
RESUMO
Este artigo tem por objetivo mostrar a importância de se reter o capital intelectual dentro de nossas organizações, através de vários comparativos, chegando a uma variável que estabelece os dez pontos de confluência sobre o capital intelectual. Este trabalho será apresentado em três momentos. Primeiramente, será realizada uma revisão bibliográfica. No segundo momento, apresentar-se-á resultados de uma pesquisa de campo realizada na empresa X do Município de Caxias do Sul. Finalmente, procurar-se-á estabelecer uma proposta de intervenção para os fatores que afetam as equipes de trabalho desta empresa.

Palavras-chave: recursos humanos; capital intelectual; gestão de pessoas e retenção de talentos.
\end{abstract}

\begin{abstract}
This article has as objective showing the importance of retain intellectual capital inside of ours organizations through many comparison, reaching a variable that establishes ten matters of confluences on intellectual knowledge. This work will be presented in three times. Firstly, there will be done a bibliographical revision. Secondly will be presented results of specific research fulfilled at the company X of Caxias do Sul City. Finally, we are looking forward to establish a proposal of intervention to factors that affect team of company workers. Keywords: human resources; intellectual capital; people management and intellectual retention.
\end{abstract}

Introdução

Com o passar do tempo, foram desenvolvidas diversas ferramentas de análise ambiental, que fornecem subsídios para a projeção de resultados a médio e longo prazo, procurando facilitar com isso a tomada de decisão estratégica dentro das organizações.

No cenário da globalização econômica, em que a competição para reter talentos é cada vez mais intensa, grandes organizações estão buscando alternativas para medir e reter seus talentos através do capital intelectual de seus funcionários, cujo principal componente envolvido é o conhecimento adquirido. Sendo assim, é preciso indicadores para mensurar o conhecimento e avaliar seu capital junto ao crescimento da empresa. Como estudos de caso, há duas empresas de porte internacional que utilizam métodos e modelos diferentes para agregar valor a esses profissionais. Nesse novo contexto faz-se necessário repensar algumas questões sobre o capital intelectual das empresas: interessa saber se o capital intelectual é a penas um modismo ou se através dele é possível

1 Aluna do curso de Pós Graduação em Gestão da Comunicação Empresarial da Faculdade Anglo-Americano de Caxias do Sul. 2 Professor orientador, Doutor em Educação e docente de Filosofia e Metodologia da Pesquisa na Faculdade Anglo Americano de Caxias do Sul. 
possuir uma ferramenta que contribui na gestão de pessoas, na retenção e potencialização dos colaboradores?

No desenvolver desta pesquisa será abordada esta questão. Além disso, objetiva-se, a partir deste estudo, mostrar ao mercado de trabalho que gerir e reter seus talentos será a nova tendência das empresas brasileiras. Porém, esse novo cenário coloca novos desafios para o $\mathrm{RH}$, isso porque se vê na maioria das empresas uma restrição relacionada ao assunto, seja por desconhecimento ou até mesmo desinteresse.

Por muito tempo a área de Recursos Humanos foi vista $e$ às vezes ainda é percebida como um subsistema que pouco contribui para a organização, sendo rotulado como um centro de custos. Com a evolução das grandes empresas e capacitação de grandes profissionais, este paradigma tem mudado. A busca para reter os talentos dentro das organizações é incansável, pois a lei da oferta e procura é cada vez mais ampla no mercado, fazendo muitas vezes com que grandes profissionais se vendem em função de benefícios e valores.

Os motivos que justificam a escolha deste assunto é que na economia de hoje, o valor é praticamente produto do conhecimento. Por consequência, um dos ativos mais apreciados e estratégicos de uma empresa é seu quadro de funcionários, aqueles que são capazes de otimizar seus conhecimentos por meio das redes mundiais.

Essa nova realidade impõe um grande desafio sobre a função da área de recursos humanos para projetar estratégias orientadas para reter e desenvolver o talento escasso. Por este motivo a recompensa total deve oferecer um pacote de remuneração que retenha estes talentos junto à organização.

Segundo Lacombe e Heilbron (2007, p. 238), selecionar, formar e integrar um grupo de pessoas para trabalharem numa empresa como verdadeira equipe, mantendo esses talentos, é a responsabilidade mais importante do administrador, pois o trabalho de formar, integrar e reter uma equipe pode levar vários anos e não há seguro contra a perda deste importante ativo para a organização.

Este trabalho será apresentado em três momentos, sendo a metodologia estudada com seus devidos autores, os quais fortalecem a pesquisa com seus esclarecimentos sobre o assunto, posterior a pesquisa realizada com gestores e consultor da área de recursos humanos, finalizando com apresentação dos dez pontos de confluência sobre capital intelectual e retenção de talentos.

\section{Administração de Recursos Humanos}

\section{Conceitos de Administração}

De acordo com Maximiano (2000, p. 30), a Teoria Geral da Administração é "o corpo de conhecimentos a respeito das organizações e do processo de administrá-las. É composta por princípios, proposições e técnicas em permanente elaboração". Não existem receitas prontas ou fórmulas. A teoria em administração é construída a partir de um conjunto de conhecimentos organizados e sistematizados, resultantes da experiência prática obtida nas organizações.

Conforme Chiavenato (2007), o mundo em que se vive é uma sociedade institucionalizada e composta por organizações. Todas as atividades relacionadas à produção de bens (produtos) ou prestação de serviço (atividade especializada) são planejadas, coordenadas, dirigidas, executadas e controladas pelas organizações. Todas as organizações são constituídas por pessoas e por recursos não humanos (como recursos físicos e materiais, financeiros, tecnológicos, mercadológicos etc.). Na sociedade moderna, as pessoas nascem, crescem, aprendem, vivem, trabalham, divertem-se, são tratadas e 
morrem dentro de organizações, as quais, muitas vezes, não valorizam o empenho e o crescimento profissional.

Para Chiavenato (2004), a TGA (teoria geral da administração), começou com a ênfase nas tarefas (atividades executadas pelos operários em uma fábrica) por meio da administração Científica de Taylor. A seguir, a preocupação básica passou para a ênfase na estrutura com a Teoria Clássica de Fayol e com a Teoria da Burocracia com Weber, seguindo-se mais tarde a Teoria Estruturalista. A reação humanística surgiu com a ênfase nas pessoas, por meio da Teoria das Relações Humanas, mais tarde desenvolvida pela Teoria Comportamental e pela Teoria do Desenvolvimento Organizacional. A ênfase no ambiente surgiu com a Teoria dos Sistemas, sendo completada pela Teoria da Contingência. Essa posteriormente desenvolveu a ênfase na tecnologia. Mas, recentemente, as novas abordagens trouxeram à tona a emergente necessidade de competitividade das organizações em um mundo globalizado e carregado de mudanças e transformações.

\section{Cultura Organizacional}

Com a dificuldade de estabelecer uma cultura, o capital intelectual dentro das empresas é visto como ditador de regras para o mercado de trabalho, remunerando condizentemente seus colaboradores, os quais estão cada vez à procura de profissionais competentes, que tenham cultura e uma base de conhecimento adquiridos em instituições de ensino de renome, excelência e qualidade.

Alguns autores entendem que a cultura organizacional é capaz de modelar as formas de gestão e os comportamentos. Implementa a prática de valores essenciais à empresa, estimula o comprometimento de seus funcionários, cria um clima propício ao trabalho e, ao mesmo tempo, é harmonioso para todos, consolidando uma base cultural interna. Ou seja, são normas e valores compartilhados pelos colaboradores que ajudam a determinar quais comportamentos são apropriados ou não. Além disso, passa por um processo de troca de informaçóes. A cultura organizacional revela caráter normativo, funcionando como um filtro para aquilo que os novos membros deverão sentir, pensar e receber.

Sabe-se que a comunicação nas empresas geralmente é feita através de jornais internos, boletins, circulares e outros meios tradicionais, mas com as novas técnicas de administração $e$ a evolução da tecnologia este cenário mudou bastante, podendo agora se utilizar das novas tecnologias de comunicação como meio $e$ instrumento para atingir seus objetivos. As telecomunicações juntamente com a Informática dão saltos de criatividade, fazendo com que o mundo diminua e o contato entre as pessoas $e$ empresas mude radicalmente. Isso é constatado, por exemplo, com o surgimento da Internet que permitiu a comunicação sem fronteiras e a troca constante de informações. O mundo está mudando rapidamente e profundamente e com isso as organizações sofrem grandes transformações.

Com a informatização dos processos administrativos e o surgimento constante de novas tecnologias, as empresas começam a redesenhar seus fluxos de informação e são sentidas mudanças no volume e nos conteúdos da informação. Com a internet passa-se agora para a Era do Conhecimento. As organizações passam a conviver com variadas iniciativas de gestão do conhecimento, o capital intelectual passa a ter grande importância na estrutura das empresas, cresce a utilização da Intranet.

$\mathrm{Na}$ atualidade, a comunicação com o público interno assume grande importância, face à produção em massa e a opção de atender mercados externos. A comunicação organizacional surge fortalecida $e$ como uma das prioridades das empresas. Ela poderá contribuir na automação de tarefas do dia a dia, no desenvolvimento de novos mecanismos de comunicação, agilizar a distribuição 
de informações pelos variados níveis hierárquicos, reduzir gastos materiais etc.

Conforme Chiavenato (2004, p. 99), cultura organizacional é um ponto de vista amplo, pois cada sociedade ou nação tem uma cultura própria que influencia o comportamento das pessoas e das organizações. A cultura de uma sociedade compreende os valores compartilhados, hábitos, usos e costumes, códigos de conduta, tradições e objetivos que são aprendidos das gerações mais velhas, impostos pelos membros atuais da sociedade e passados sucessivamente para as novas gerações. As gerações mais velhas tentam adaptar as gerações mais novas aos seus padrões culturais, enquanto essas resistem $e$ reagem, provocando mudanças e transformações gradativas. Esse compartilhamento de atitudes comuns, código de conduta e expectativas passa a guiar e a controlar subconscientemente certas normas de comportamento, ou seja, as variáveis culturais, por sua vez, determinam as atitudes básicas em relação ao trabalho, tempo, materialismo, individualismo e mudança. Tais atitudes afetam a motivação $e$ as expectativas das pessoas quanto ao trabalho e relações grupais e estas afetam os resultados que se podem esperar de cada pessoa. Além disso, a cultura influencia e condiciona poderosamente as interações entre as pessoas e o processo de comunicação.

\section{Evolução da Área de Recursos Humanos}

Há pouco tempo o relacionamento entre pessoas e organização era considerado antagônico e conflitivo. Acreditava-se que os objetivos das organizações eram apenas com lucro, produtividade, maximização de recursos e redução de custos, ou seja, eram incompatíveis com os objetivos individuais das pessoas: benefícios, lazer, segurança no trabalho e desenvolvimento e progresso de pessoas.

Pode-se dizer que manter-se alinhado à estratégia de negócios da organização tem sido, nos últimos tempos, um dos principais desafios dos profissionais de recursos humanos.
Nesse percurso, o setor deixou de lado funções operacionais e passou a atuar efetivamente na linha de frente da estratégia de negócios, na qual acumulou, entre outras, a missão de desenvolver pessoas e promover mudanças significativas dentro dos demais setores da corporação.

Como as máquinas de escrever deram lugar aos computadores, o RH também precisou se render à modernidade. $\mathrm{O} \mathrm{RH}$ de hoje apresenta uma postura atuante dentro dos processos estratégicos da organização, uma vez que as empresas passaram a descobrir que seu maior patrimônio está no desenvolvimento do seu capital humano. Mas, apesar de toda essa transformação ocorrida no setor nos últimos anos, ainda há três tipos de RHs: os que fazem as coisas acontecerem, os que apenas vêem acontecerem e os que simplesmente nem sabem que as coisas estão acontecendo.

Chiavenato (2004, p. 141) salienta que não há um sistema único ou normatizado sobre os conceitos de $\mathrm{RH}$, variando de acordo com os fatores externos e internos em que a organização está inserida. As transformações que vêm ocorrendo no mundo do trabalho demandam às áreas de $\mathrm{RH}$ notável esforço no sentido de repensarem suas funções, papéis e forma de atuar, vinculando suas ações aos objetivos estratégicos organizacionais e à gestão de mudanças. Tornando-se central o alinhamento da estratégia organizacional com as estratégias e políticas de recursos humanos.

Atualmente, as organizações estão ampliando sua visão e atuação estratégica. Todo processo produtivo somente se realiza com a participação conjunta de diversos parceiros, cada qual contribuindo com matérias-primas, insumos básicos, serviços e tecnologias. Mas, certamente, sabe-se que o parceiro mais íntimo da organização é o empregado, isto é, aquele que está dentro da organização, que lhe dá vida e dinamismo e que faz as coisas acontecerem.

Nas indústrias neoclássicas, surgem os departamentos de recursos humanos que 
substituem os antigos departamentos de relações industriais. Além das tarefas operacionais e burocráticas, os chamados DRH desenvolvem funções operacionais e táticas, como órgãos prestadores de serviços especializados. Cuidam do recrutamento, seleção, treinamento, avaliação, remuneração, higiene e segurança do trabalho $e$ de relações trabalhistas e sindicais, com variadas doses de centralização e monopólio dessas atividades. Na era da informação, surgem as equipes de gestão com pessoas, os quais substituem os departamentos de recursos humanos e de gestão de pessoas.

\section{As Fases Evolutivas de Gestão de Pessoas}

Segundo Marras (2003, p. 25); acompanhando as diferentes mudanças nas titulações e no conjunto de responsabilidades inerentes à função de pessoal, o ocupante dessa posição, como era de esperar, também sofreu uma evolução natural no desenvolvimento de seu perfil "personal" e cultural, de forma a poder acompanhar as mudanças exigidas a cada nova fase desse importante trabalho. Foi na fase legalista, na década de 30, que o cargo passou realmente a exigir um ocupante típico para as funções de pessoal.

De acordo com Marras (2003, p. 26)na fase tecnicista (1950 a 1965), o perfil desse profissional teve outra mudança significativa. Surgiu, assim, o primeiro e verdadeiro administrador de pessoal. As organizações passaram a privilegiar, em seus recrutamentos, profissionais com currículos escolares mais amplos e começaram a admitir a importância de profissionais com leve visão humanista, características fundamentais para exercer as funções. Na fase administrativa (1965 a 1985), verificou-se a consolidação definitiva de formação cultural e educacional do perfil do gestor de recursos humanos como administrador de empresa. Nessa fase, as organizações passaram a exigir dos profissionais de recursos humanos um conhecimento profundo $e$ atualizado dos aspectos trabalhistas legais. Já na fase estratégica, após 1985, o administrador de empresas retomou a sua posição nos organogramas da empresa, dessa vez de forma definitiva. Exigia-se do profissional de recursos humanos um perfil cognitivo que lhe permitia analisar cenários multidisciplinares nos indivíduos, não mais como simples trabalhadores assalariados, mas como "parceiros" do negócio, responsáveis, portanto, por uma parcela significativa dos resultados projetados. Iniciou-se aqui a fase nobre $e$ mais interessante do administrador de recursos humanos.

Para Gil (2007, p. 17), a Gestão de Pessoas é a função que visa à cooperação das pessoas que atuam nas organizações para o alcance dos objetivos tanto organizacionais quanto individuais. Constitui-se, a rigor, uma evolução das áreas designadas no passado como Administração de Pessoas, Relações Industriais e Administração de Recursos Humanos. Essa expressão aparece no final do século XX e guarda similaridade com outras que também vêm se popularizando, tais como Gestão de Talentos, Gestão de Parceiros e Gestão do Capital Humano.

De acordo com Chiavenato (2004, p. 138), a administração de recursos humanos consiste no planejamento, organização, desenvolvimento, coordenação e controle de técnicas capazes de promover o desempenho eficiente do pessoal, ao mesmo tempo em que a organização constitui o meio que permite às pessoas que com ela colaboram alcançar os objetivos individuais relacionados direta ou indiretamente ao trabalho. A administração de recursos humanos busca conquistar e manter pessoas na organização, trabalhando e dando o máximo de si, com uma atitude positiva e favorável: "Os administradores são aqueles que com e através das pessoas, distribuindo recursos, no esforço para alcançarem objetivos. Eles cumprem suas tarefas através de quatro atividades criticas: planejamento, organização, direção e controle." (DE CENZO; ROBBINS, 2001, p. 2). 
Chiavenato (2004, p. 212), afirma que a administração de recursos humanos provoca impacto nas pessoas e nas organizações. A maneira de lidar com as pessoas, de buscá-las no mercado, de integrá-las e orientá-las, fazê-las trabalhar, desenvolvê-las, recompensá-las ou monitorá-las, ou seja, a qualidade da maneira como as pessoas são geridas na organização, é um aspecto crucial na competitividade organizacional.

Os processos básicos na gestão de pessoas são cinco: prover, aplicar, manter, desenvolver e monitorar as pessoas. Sua interação faz com que qualquer alteração ocorrida em algum deles influencie sobre os demais.

Cinco processos básicos:

\begin{tabular}{|l||l|l||l|l|}
\hline \multicolumn{1}{|c|}{ Provisão } & \multicolumn{1}{|c|}{ Aplicação } & Manutenção & Desenvolvimento & Monitoração \\
\hline $\begin{array}{l}\text { Quem irá trabalhar na } \\
\text { organização }\end{array}$ & $\begin{array}{l}\text { O que as pessoas } \\
\text { farão na organização }\end{array}$ & $\begin{array}{l}\text { Como manter as pessoas trabal- } \\
\text { hando na organização }\end{array}$ & $\begin{array}{l}\text { Como preparar e } \\
\text { manter as pessoas na } \\
\text { organização }\end{array}$ & $\begin{array}{l}\text { Como saber o } \\
\text { que são e que } \\
\text { fazem as pessoas }\end{array}$ \\
\hline $\begin{array}{l}\text { *Pesquisa de mercado } \\
\text { *Recrutamento*Seleção }\end{array}$ & $\begin{array}{l}\text { *Programa de inte- } \\
\text { gração *Desenho de } \\
\text { cargos*Avaliação de } \\
\text { desempenho }\end{array}$ & $\begin{array}{l}\text { *Remuneração*Benefícios } \\
\text { Rociais *Higiene e segurança } \\
\text { *Relações sindicais }\end{array}$ & $\begin{array}{l}\text { *Treinamento } \\
\text { *Desenvolvimento } \\
\text { organizacional }\end{array}$ & $\begin{array}{l}\text { *Sistema de } \\
\text { informação } \\
\text { *Controles e } \\
\text { auditoria de } \\
\text { pessoal }\end{array}$ \\
\hline
\end{tabular}

QUADRO 01: PROCESSO GLOBAL DA ARH.

FONTE: CHIAVENATO (2004, P. 137).

Os cinco subsistemas formam um processo global e dinâmico através do qual as pessoas são captadas e atraídas, aplicadas em suas tarefas, mantidas na organização, desenvolvidas e monitoradas pela organização.

\section{Capital Intelectual}

Segundo Gil (2007, p. 46), à medida que se reconhece ser o principal capital da empresa o intelectual, é razoável admitir que ela estará cada vez mais sujeita a perder seus empregados para outras empresas. Dessa forma a evasão de talentos pode afetar negativamente os processos de inovação. Fica claro que a evasão de talentos não poderá ser evitada mediante apenas a compensação salarial, mas também se fará necessário criar condições para que os capitais intelectuais permaneçam nas empresas.

Segundo sócio diretor da RGM Educação e Marketing, Sr. Luiz Fernando Reginato, podem se considerados como talentos plenos aqueles profissionais que conjugam potencial de conhecimento com desempenho superior na realização de resultado. Seguramente, estes recursos humanos serão chaves para o sucesso das empresas e será muito bom mantê-los. Pois, segundo ele, outro ponto de evolução na gestão do capital intelectual é o reconhecimento de talentos por um processo democrático sem fronteiras, nem barreiras, capaz de aflorar competências ocultas em qualquer lugar da empresa.
O conhecimento, material intelectual bruto, transforma-se em capital intelectual, a partir do momento que passa a agregar valor aos produtos/serviços. E esse capital é, em alguns casos, mais valioso do que o próprio capital econômico. Não existe unanimidade quanto à definição do capital intelectual.

Para Stewart (1998:XIII), capital intelectual "é a soma do conhecimento de todos em uma empresa, o que lhe proporciona vantagem competitiva. [...] constitui a matéria intelectual - conhecimento, informação, propriedade intelectual, experiência que pode ser utilizada para gerar riqueza".

Segundo Edvinsson e Malone (1998), o capital intelectual é a soma do capital humano e do capital estrutural $(\mathrm{CI}=\mathrm{CH}+\mathrm{CE})$. O capital intelectual surge do intercâmbio entre esses dois. 
- Capital Humano: corresponde a toda capacidade, conhecimento, habilidade e experiência individual dos empregados de uma organização para realizar as tarefas. Não pode ser propriedade da empresa representada assim a parte mais difícil do modelo de capital intelectual.

- Capital Estrutural: é formado pela infraestrutura que apoia o capital humano, como equipamentos de informática, software, banco de dados, reder etc. Esses autores usam a metáfora da árvore para melhor explicar o capital intelectual, fazendo a seguinte analogia:

FRUTOS = LUCROS;

FOLHAS, GALHOS E TRONCO = representam a empresa conforme é conhecida pelo mercado e expressa pelo tronco contábil (parte visível); (valor oculto).

RAIZ = CAPITAL INTELECTUAL

Para ter bons frutos, a árvore precisa ser alimentada por raízes fortes e sólidas. Com raízes bem cuidadas, a empresa florescerá. Já com raízes avariadas a empresa poderá morrer. Raízes fortes podem constituir o único fator que preserva uma árvore durante uma seca ou uma geada inesperada.

Para Nonaka e Takeuchi (1997), capital intelectual/conhecimento é um ativo intangível que está disperso na cabeça das pessoas que integram uma empresa e em documentos gerados em sua estrutura, como relatórios, memorandos, arquivos eletrônicos e, especialmente, na sua experiência prática. Esses autores conceituam o conhecimento explícito (existência concreta) e o conhecimento tácito (intuitivo).

\section{A Importância de Medir e Reter Capital Intelec- tual}

A Revista RH, edição do mês de abril, teve como enfoque "As pessoas no balanço". Segundo os autores Hélio Batista Barbosa e Gumae Carvalho, é cada vez mais frequente, na Europa e nos EUA, calcular o valor do capital intelectual, que promete ser a nova tendência no Brasil nos próximos anos. Segundo os autores, os gastos com os funcionários não serão mais considerados como despesas ou custos, mas sim como investimento, pois os recursos humanos passarão a ser contabilizados conforme a exata definição da palavra recursos, ou seja, como um ativo.

Tal perspectiva constitui a base do conceito de gestão do valor humano e da chamada contabilidade estratégica dos recursos humanos, pois, na era da tecnologia da informação, nada proporciona mais resultados a uma empresa do que o estoque do conhecimento acumulado pelos funcionários, sendo essa a tendência do século XXI. Tal perspectiva foi profetizada pelo papa da administração norte-americano, Peter Drucker. Um grande exemplo disto é que muitas empresa possuem valor de mercado várias vezes maior do que o total de seus bens, bastando lembrar ícones como Microsoft, Google, IBM etc.

O capital intelectual é uma realidade da qual não se pode mais fugir. A sua influência na gestão empresarial fez surgir um novo código de comportamento e uma nova atitude em relação ao mesmo. Vive-se um momento de importante transição do ambiente econômico, porque a gestão pró-ativa do conhecimento adquire um papel central para a competitividade tanto das empresas, como dos países. A gestão do conhecimento vai muito além do investimento em tecnologia ou gerenciamento da inovação. Assim, faz-se necessário esclarecer o desafio maior do momento que consiste em tentar estabelecer padrões para a medição do capital intelectual e testar a sua viabilidade no contexto organizacional.

É por isso que, num futuro próximo, as informações sobre o capital intelectual estarão mudando a concepção, do balanço patrimonial e da demonstração do resultado do exercício. Percebe-se que há um processo em construção, que necessita ser avaliado e compreendido pelas pessoas, para que essas comecem a raciocinar dentro dessa nova lógica de avaliação e mensu- 
ração. Talvez seja por isso que as empresas do conhecimento eliminam cada vez mais ativos fixos de seus balanços, para esse tipo de empresa, quanto menos ativo melhor, desde que se tenha capital intelectual.

São vantagens:

- aumento do potencial contabilizado;

- clareza e adequação;

- facilita a escolha do investidor;

- determina de que maneira uma melhor gestão do conhecimento ajudará a empresa ganhar e economizar dinheiro;

- evitar danos e injustiças.

Ativos corporativos intangíveis (Capital Intelectual)

Segundo Thomas Stewart (1998), o capital intelectual é denominado como bens intangíveis pelos contadores é calculado usando-se a fórmula do Capital Intelectual = Capital Humano + Capital Estrutural. existem dentro da empresa e entre ela e seus outros parceiros; pelo capital de relacionamento, ligado aos fornecedores, clientes, prestadores de serviços e outros parceiros, principais envolvidos; e pelo capital de inovação, uma consequência direta da cultura da empresa e de sua capacidade de criar conhecimento novo como base no conhecimento existente. A fórmula é a seguinte: CAPITAL ESTRUTURAL = CAPITAL DE PROCESSOS $=$

CAPITAL DE RELACIONAMENTO = CAPITAL DE INOVAÇÃO.

A fórmula utilizada nas grandes organizações para se medir o capital intelectual das incorporações é CAPITAL INTELECTUAL = CAPITAL HUMANO + CAPITAL DE PROCESSOS + CAPITAL DE RELACIONAMENTO + CAPITAL DE INOVAÇÃO.

Segue abaixo o organograma visto por estas organizações:

Reconsiderando alguns fatores como métodos de avaliação e indicadores, o que se percebe é que, por mais que os gestores de

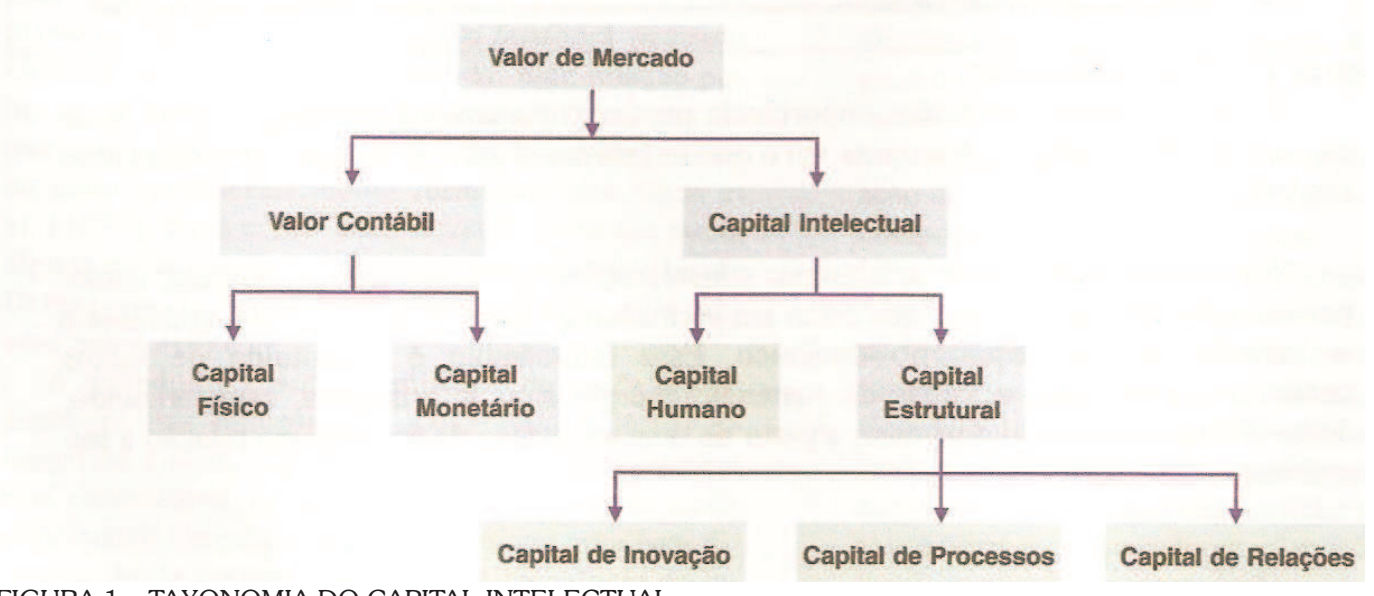

FIGURA 1 - TAXONOMIA DO CAPITAL INTELECTUAL

O capital humano não pertence à empresa, pois é consequência direta da soma das habilidades e especialidades de seus empregados. O capital estrutural pertence à empresa e pode ser negociado. $\mathrm{O}$ ambiente real construído pela companhia para administrar e gerar seu conhecimento de forma adequada é composto por todos os processos internos e externos que

RH gostem de repetir o "dito popular" os funcionários são o patrimônio da empresa, a contabilidade ainda não conseguiu traduzir isso em termos práticos e exatos por completo. As tentativas que chegaram mais perto dessa revolução não conseguiram se disseminar e se consolidar.

Segundo artigo extraído da Revista Melhor de Pessoas, o Sr. Alberto Mondelli, que é líder Regional da área de Capital Humano da 
América Latina, os modelos de gestão que darão lucros, no futuro próximo, é a gestão do capital intelectual, pois esta irá satisfazer as necessidades dos modelos específicos de lucro, pois os profissionais de $\mathrm{RH}$ não irão apenas apoiar o desempenho dos negócios, mas também auxiliara a empresa a medir e reter seus talentos, através do capital intelectual de seus colaboradores agregado ao ativo das organizações.

A gestão de pessoas evolui bastante do ponto de vista estratégico, mas as ferramentas de avaliação ainda estão em evolução. O grande responsável por essa deficiência contábil é o conjunto de recursos intelectuais que correspondem aos ativos mais valiosos encontrados nas empresas e que não vêm sendo levados em conta pela contabilidade. A questão não é o desconhecimento ou mesmo o desprezo dessa nova realidade, e sim a dificuldade de se encontrar uma metodologia segura e adequada para mensurar e avaliar esse novo recurso econômico gerador de riqueza da sua natureza intangível.

Mas, no Brasil, tem-se uma empresa pioneira em mensurar este valor, a Companhia Paulista de Trens Metropolitanos (CPTM), desde 2000, está procurando contemplar em seus balanços três valores: o Balanço Patrimonial, a relação clássica de ativos e passivos; o Balanço Social, que evidencia sua ação junto à sociedade e o Balanço Intelectual, em que usa o conhecimento como importante recurso agregador de produtividade.

Essa iniciativa partiu da área contábil, que precisa encontrar uma forma de medir o capital intelectual da organização. A partir desse ano, o projeto de desenvolvimento do balanço intelectual terá a participação de uma equipe multifuncional, envolvendo profissionais das mais diversas áreas, com isso pretende-se motivar todos os setores e obter mais informações para o balanço intelectual de 2008 .

É importante salientar que medir o capital intelectual é uma realidade desde 1994, quando a empresa sueca Skandia criou uma diretoria de capital intelectual, que preparou o primeiro balanço do gênero. Hoje, Alemanha, Espanha, Estados Unidos e até a Colômbia realizam análises sobre o capital intelectual e gestão do conhecimento.

Segundo Carlito Kerling:

"Aquilo que não se consegue medir, não se consegue melhorar".

Pesquisa de campo: questões norteadoras sobre o capital intelectual das empresas - Investigação a partir do contexto de duas montadoras multinacionais de Caxias do Sul

Nesta análise, serão apresentados os resultados da pesquisa de campo realizada na cidade de Caxias do Sul. O objetivo da aplicação dos questionários foi uma maior compreensão dos gestores a respeito do capital intelectual de suas organizações. Foi desenvolvido um questionário somente para os gestores de Recursos Humanos. Ele engloba cinco questões de análise qualitativa e nele o gestor descreve suas vivências, tendências de mercado, avaliando os postos fundamentais.

As empresas entrevistadas são do ramo metal mecânico, tradicional de Caxias do Sul. São grandes multinacionais, ambas com mais de 5000 mil funcionários. Fortes nas áreas de montadora, pois trabalham com importação $e$ exportação e possuem filiais e representantes em quase todo continente. Investem fortemente em treinamento para suas equipes de trabalho. Além disso, ambas são familiares. Existe um diferencial de gerenciamento entre elas. Uma prepara seus sucessores para a próxima geração dentro da família; a outra busca concentrar bons profissionais no mercado de trabalho. Elas são empresas que muitos trabalhadores se orgulham de fazer parte. Isso acorre porque há a existência de projetos como BSC (Balanced Scorecard), 
que oportuniza o crescimento e evolução de seus colaboradores, deixando claro onde podem chegar.

Questionário Aplicado aos Gestores de Recursos Humanos

1. Com a globalização e a troca de experiências, qual o seu posicionamento em relação à questão "A importância de reter talentos através do capital intelectual".

2. Quais os processos utilizados pela empresa onde você atua para reter seus capitais intelectuais na organização?

3. Você acha que é possível a empresa contabilizar o valor estimado deste capital e agregá-lo ao seu balanço. De que forma?

4. Em sua opinião, essa nova tendência veio para permanecer no mercado de trabalho ou será apenas mais o modismo?

5. Grandes empresários de empresas multinacionais, como FORD, XEROX e outras, têm a visão de que esta nova tendência servirá não somente para reter estes capitais intelectuais, mas principalmente para fortalecer o nome da companhia junto ao mercado. Em sua opinião, isso é provável?

\section{A importância de reter talentos}

Com a chegada da informatização na área de capacitação, seleção e retenção de talentos tem se levado empresas e candidatos a mudanças na forma de fazer suas ofertas no mercado de trabalho e especificamente ao de recursos humanos.

Conforme os gestores entrevistados, a globalização exige e exigirá talentos. As empresas necessitam cada vez mais deles para vencer os seus desafios e alcançar o sucesso. Neste cenário, talvez o maior desafio seja o de transformar as pessoas no segredo deste sucesso. Para isso, é necessário desenvolvê-las e estimulá-las a terem a capacidade de assegurar os resultados que a empresa espera delas.

É preciso, além de atrair e desenvolver, reter os talentos. Para isso é importante que se invista em treinamentos, cursos de desenvolvimento, dando aos talentos a oportunidade de utilizar a sua plena capacidade de criatividade de proporcionar oportunidades desafiadoras, pois a grande maioria dos profissionais extremamente qualificados somente permanece no emprego se vislumbrarem oportunidades que lhe propiciem desafios.

Pode-se afirmar que desenvolvimento de talentos já não é mais uma diferenciação, mas sim uma questão de sobrevivência. Além disso, a vantagem competitiva está exatamente para aquelas organizações que souberem atrair, desenvolver e reter os seus talentos.

Um dado que deve ser considerado importante neste contexto é que talento não é apenas alguém que se destaca profissionalmente. Talento refere-se ao profissional que sabe cultivar o seu lado pessoal e acima de tudo, aquele que consegue ter qualidade de vida.

Processos utilizados para reter capitais intelectuais na organização

As organizações precisam dispor de pessoas competentes e motivadas para produzirem. Por isso, é necessário ter uma escala de benefícios, treinamentos, desenvolvimento, planos de carreira e muitos outros para reter os talentos junto à organização, embora muitas vezes isto por si só não baste.

Para os gestores, uma empresa do porte destas, com um posicionamento estratégico muito bem definido, precisa, já neste planejamento, pensar nas pessoas. É através delas que os negócios irão acontecer. 
A empresa define anualmente as funções que são estratégicas para o sucesso de seus negócios. Não significa dizer que existem funções que não sejam estratégicas. Há aquelas que se não forem trabalhadas de forma altamente diferenciada, impedirão a realização dos os resultados esperados. Para essas funções existe um plano de desenvolvimento diferenciado $e$ nelas são desenvolvidas as habilidades técnicas e comportamentais através de programas de desenvolvimento com parceiros educacionais. Todo este programa está perfeitamente alinhado ao planejamento da empresa.

Todos os demais programas de qualificação dos colaboradores da empresa estão também alinhados às estratégias da empresa. Ex: Programa de Desenvolvimento de Supervisores.

A retenção se dá com:

- Plano de benefícios bem estruturado. Há três opções de plano. O funcionário escolhe qual o melhor para ele. Isto atrai e retém;

- Plano de Carreira: o funcionário pode vislumbrar o crescimento profissional e consequentemente melhorar a sua própria qualidade de vida;

- Programas de treinamento e desenvolvimento: o funcionário recebe oportunidade de treinamento, estimulado pela liderança;

- Fundação: possui inúmeros programas sociais, que envolvem os trabalhadores e seus familiares. Esses programas aproximam a família à empresa. Aumentam o orgulho de pertencer à organização através do apoio da familiar;

- Programa de recrutamento interno: antes da contratação é verificada a existência deste profissional dentro da empresa para ocupar a vaga; - Código de Ética: todos sabem qual o comportamento esperado, em todos os níveis, com relação aos processos corporativos da empresa;

Canal de Ouvidoria: as manifestações são feitas e é dado um tratamento para cada uma. É a segurança que o colaborador tem com relação às questões éticas de assédio moral, sexual, discriminações e outros.

Extensão em Foco, Curitiba, n. 7, p. 55-71, jan./jun. 2011. Editora UFPR
A importância de contabilizar o capital intelectual

A sua influência na gestão empresarial fez surgir um código de comportamento e uma nova atitude em relação ao assunto capital intelectual, as empresas, atualmente, já estão contabilizando seus talentos e os agregando aos seus balanços, acrescentando-os como metas no planejamento estratégico das grandes corporações.

Segundo os gestores talvez seja difícil quantificar estas ações em números. Mas se se considerar, por exemplo, os índices de rentabilidade das empresas classificadas entre as melhores para se trabalhar - (Revista Exame 2008) - e comparar com as empresas que não estão entre essas, você verá que as que estão apresentam melhores índices. Se você olhar o que estas empresas estão fazendo, notará que todas as ações são de atração e retenção de talentos, com excelentes programas de benefícios.

\section{Nova tendência ou modismo}

O sucesso da qualidade vai além das ferramentas de trabalho e consiste em mudar a capacidade do ser humano de interpretar $e$ medir seus potenciais. Desde a existência do ser humano, se está sempre testando e buscando a melhoria contínua, desta forma acompanhamos o crescimento de várias áreas, principalmente a evolução do RH. Até o presente momento, tudo o que foi criado foi posto em prática nas organizações para o bem estar de seus colaboradores.

$\mathrm{Na}$ opinião dos gestores, a retenção de talentos veio para ficar, principalmente nos dias de hoje, onde há uma grande escassez de profissionais qualificados. Não dá para pensar em competitividade sem pensar em talentos. $\mathrm{O}$ diferencial das empresas que querem perpetuar o seu negócio está na capacidade de qualificar, reter e atrair talentos.

Não acreditam em modismo. E retratam que a tendência de gerir e reter talentos dentro do capital intelectual das empresas veio 
para se mostrar ao mercado. Aliás, pensam que os grandes responsáveis pela manutenção dos talentos, são os profissionais de $\mathrm{RH}$. Cabe a eles implementar, estudar, propor projetos, programas, ações, que visem exatamente a manutenção e atração de profissionais qualificados. Estes programas devem estar alinhados a toda a estratégia da empresa.

Retenção dos capitais com o fortalecimento das companhias junto ao mercado

Sabe-se que nos dias atuais o grande negócio são as pessoas, as quais precisam ser motivadas e controladas. Nas grandes organizações, não é diferente, pois a empresa que valoriza e retém seus talentos, de certa forma é bem vista no mundo.

Segundo os gestores, não há dúvidas de que o grande desafio das empresas é a retenção de talentos. Além disso, o fortalecimento do nome da empresa não está somente na dependência disso. Há inúmeros outros fatores: imagem institucional, credibilidade, gestão do meio ambiente.

É claro que não se pode esquecer que uma empresa só é empresa com pessoas, e como tal devem sim preservar, atrair, manter seus talentos. Cabe destacar que o capital intelectual também é encontrado nos processos, produtos, serviços e esse também devem ser preservados, com políticas de segurança da informação, evitando assim que isto caia em mãos erradas.

Nos planos estratégicos, a retenção tem surgido como um dos objetivos mais importantes. O primeiro passo para que se possa agir e suprir essa necessidade é um entendimento comum de quem são, de fato, os talentos para a empresa. Entendem que todas as pessoas são talentos numa empresa. O que as diferenciam é a forma da manifestação de seus talentos.

Se todos são talentos, é importante não esquecer que somente quando a manifestação do talento individual está alinhada com os valores, a missão, a visão e as necessidades presentes e futuras da empresa pode-se dizer que se está frente a uma pessoa com o talento desejado.

Independentemente da empresa, ela necessita hoje e continuará precisando no futuro de talentos em todas as funções e carreiras. Dificilmente se conseguirá atingir as metas da empresa sem líderes talentosos. Não basta que existam equipes competentes. São necessários líderes que de fato obtenham resultados concretos, positivos e significativos por meio das pessoas. Líderes que reúnam competências técnicas, administrativas, interpessoais e políticas para alinhar todos os propósitos individuais em uma única direção: a da visão da empresa.

\section{Considerações finais}

Ao expor o desenvolvimento desta análise, o objetivo principal era o de mostrar ao mercado de trabalho que gerir e reter seus talentos será a nova tendência das empresas brasileiras. Juntamente com o novo desafio para os recursos humanos, isso porque, na maioria das empresas, este assunto ainda não está ao alcance de todos, seja por desconhecimento ou até mesmo desinteresse. Estes objetivos foram alcançados no momento em que se depara com a quantidade de empresas que já utilizam este processo sem saber de sua existência, ou seja, o utilizam informalmente, o que me causou tamanha estranheza. Por completo, até o presente momento, o objetivo principal ainda não foi alcançado, mas tenho a certeza que ao findar este trabalho terei subsídios suficientes para pautar minha tese.

Foram levadas em consideração várias hipóteses sobre este assunto sendo que a primeira foi: A quebra do paradigma "Tendência ou modismo: reter talentos nas organizações?", havendo de certa forma um consenso unânime entre os gestores de que reter o capital intelectual das empresas veio para

Extensão em Foco, Curitiba, n. 7, p. 55-71, jan./jun. 2011. Editora UFPR 
perpetuar-se no atual mercado de trabalho. Em seguida, os processos utilizados, ou seja, indicadores e a possibilidade de agregar estes talentos ao balanço das organizações, porque as pessoas são o bem maior das empresas, viu-se que muitas já utilizam processos para acompanhar e medir suas atividades.

Uma organização é formada por pessoas que contribuem para o seu processo produtivo. Estas pessoas esperam que a organização forneça subsídios para que elas possam crescer pessoal e profissionalmente. Em contrapartida, a organização espera delas também um desenvolvimento pessoal e profissional para que apresente resultados satisfatórios na organização e perpetuem junto a ela.

No decorrer deste trabalho, obtive um grande aprendizado referente ao assunto estudado "Retenção do capital intelectual das organizações". Possibilitando obter um melhor entendimento sobre o funcionamento da empresas, suas falhas e qualidades, bem como as melhorias que podem ser implantadas para o crescimento e desempenho das mesmas. Chegando assim a algumas concordâncias com o autor estudado, Gil (2007, p. 46), que afirma que "a medida que se reconhece ser o principal capital da empresa o intelectual, é razoável admitir que ela estará cada vez mais sujeita a perder seus empregados para outras empresas, sendo assim a evasão de talentos pode afetar negativamente os processos de inovação" ficando claro que a evasão de talentos não poderá ser evitada mediante a compensação salarial, mas também se fará necessário criar condições para que os capitais intelectuais permaneçam nas empresas.

A respeito do capital intelectual, não é possível desconhecer o efeito do capital intelectual sobre as organizações, buscando assim urgentemente formas diferentes dos atuais procedimentos contábeis para reconhecer o verdadeiro valor de um profissional para sua empresa. Concordando de certa forma com o sócio diretor da RGM Educação e Marketing, Sr. Luiz Fernando Reginato, quando afirma que a evolução na gestão do capital intelectual é o reconhecimento de talentos por um processo democrático sem fronteiras, nem barreiras, capaz de aflorar competências ocultas, em qualquer lugar da empresa.

Para os gestores existem as organizações que precisam dispor de pessoas competentes e motivadas para produzirem. Dessa forma, é necessário ter uma escala de benefícios, treinamentos, desenvolvimento, planos de carreira e muitos outros para reter estes talentos junto às organizações embora, muitas vezes, isto por si só não baste.

Para os gestores, uma empresa precisa pensar nas pessoas e ter processos bem definidos, já na execução de seu planejamento estratégico, pois é através das pessoas que seus negócios irão progredir ou regredir. Definindo seu plano de ação para reter seus talentos através de programas de desenvolvimento com parceiros educacionais, programa de desenvolvimento de supervisores e programas de desenvolvimento individual, tais como: plano de benefícios bem estruturado; plano de carreira; programas de treinamento e desenvolvimento; programas de recrutamentos internos; canal de ouvidoria e muitos outros.

Tais programas constituem a base do conceito de gestão do valor humano e da chamada contabilidade estratégica dos recursos humanos.

Embora respeite à opinião do Professor e economista inglês Sr. Ralph Stacey (JANELAWEB 2002), discordo quando ele afirma que "Gestão do Conhecimento é um absurdo e medir o Capital Intelectual é desperdício de tempo e dinheiro", pois imagine uma grande multinacional que treina, capacita e investe em seus colaboradores, que pretende abrir uma filial em outro país, e pede para um profissional que efetue um estudo de probabilidade para tal investimento. Porém, certo 
dia este profissional chega à empresa e pede demissão para trabalhar em sua concorrente, em função não somente de salário, mas benefícios e qualidade de vida, então pense no valor que este profissional tem para esta empresa. Por isso acredita-se que as pessoas devem sim ser treinadas, capacitadas e medidas para chegarmos à conclusão de que todos possuem seu valor junto às organizações, havendo assim um valor agregado ao capital intelectual para cada ser humano.

Estou convicta de que a gestão de pessoas evoluiu bastante do ponto de vista estratégico, mas as ferramentas de avaliação ainda estão em evolução. Porém, o grande responsável por essa deficiência contábil é o conjunto de recursos intelectuais que correspondem aos ativos mais valiosos encontrados nas empresas e que não vêm sendo levados em conta pela contabilidade.

Pois para que a contabilidade atinja bem seus objetivos deve fornecer não só informações monetárias, mas também informações não monetárias que sejam úteis aos seus usuários. Buscando assim um modelo contábil que identifique os elementos formadores do capital intelectual, mas por outro lado não se pode pensar ou dizer que a contabilidade atual seja totalmente errada, fazendo isso se estará desmerecendo injustamente todo o desenvolvimento desta categoria.

Todavia não se pode deixar de reconhecer a necessidade de esclarecimento sobre o assunto $e$ a necessidade de mudança referente à quebra de alguns paradigmas como: não saber se posicionar sobre o assunto; não estar preparando para esta nova tendência, sejam elas aplicadas em empresas de grande, médio ou pequeno porte. É preciso saber quanto valem nossos capitais intelectuais dentro de nossas organizações.

Ficam algumas dúvidas referentes à cultura organizacional de cada empresa, pois as empresas de grande e médio porte têm conhecimento de que a evolução se faz necessária e de que ambas precisam se adequar ao novo mercado, portanto precisam de cultura para absorver estas tendências. Mas as empresas de pequeno porte terão estrutura, saberão discernir sobre o assunto com seus colaboradores,? Sendo assim, haverá garantia de satisfação e retenção de talentos e conseqeentemente, melhoria qualidade nos serviços prestados pelas organizações?

\section{Proposta de intervenção}

Sugere-se que as organizações busquem um melhor entendimento sobre o assunto, através de livros, palestras, debates, fórum ou até mesmo consultores, como Sr. Mauricio Naomi Monakara, japonês naturalizado brasileiro, consultor de empresas e grande estudioso sobre o assunto Retenção do Capital Intelectual das Organizações, pois segundo ele este é um assunto ainda pouco debatido no Rio Grande do Sul. No presente momento as grandes corporações são as que estão preocupadas com o assunto no momento.

A FIRGES (Federação das Indústrias do Rio Grande do Sul) recentemente lançou o $9^{\circ}$ Fórum de Gestão de Pessoas, com o tema "O nosso Capital Intelectual", convidando para presidir o evento grandes nomes como: Diretores de Recursos Humanos do Grupo Randon e Grupo Guerdar. Eles puderam expor suas preocupações e tendências para reter os talentos dentro de suas organizações. Segundo eles quem traça sua carreira dentro das organizações é você mesmo, o que fica para a empresa é como reter e manter seus colaboradores dentro das organizações.

Com o propósito de estabelecer um debate entre outras organizações, deixando assim um legado a ser levado em consideração, 
estabeleço os dez pontos de confluências sobre capital intelectual e retenção de pessoal.

\section{Dez Pontos de Confluência sobre Capital Intelectual e Retenção de Talentos}

\section{Trabalhar Cultura Organizacional: Com o} objetivo de explicar que quando se sugere a retenção de talentos nas organizações, ocorrerá todo um processo de mudança cultural numa organização, e por isso, é de grande pertinência estudar a cultura da organização, levando em consideração se seus diretores possuem esta abertura ou quebra de paradigmas. Ou seja, são normas e valores compartilhados pelos colaboradores que ajudam a determinar quais comportamentos são apropriados ou não. $\mathrm{A}$ cultura organizacional revela caráter normativo, funcionando como um filtro para aquilo que os novos membros deverão sentir, pensar e receber. 2. Importância sobre o Tema Retenção de Talentos: a organização tem que ter em mente a importância do assunto, buscando assim adequar de maneira correta qual o processo utilizado para sua empresa. Portanto, este assunto deve ser trabalhado em conjunto com outras áreas, havendo assim um trabalho em equipe entre os setores de direção, contabilidade e recursos humanos. Todos devem chegar ao mesmo consenso no final para que este projeto venha perpetuar na empresa. Fazendo assim com que este assunto venha a fazer parte da mesma, como a mesma importância do planejamento estratégico.

3. Empresa Sustentável: nos dias atuais é de grande importância a empresa passar segurança ao colaborador, pois, segundo pesquisa realizada pela Revista Amanhã, o colaborador ao saber que sua empresa se compromete com os princípios da sustentabilidade, torna-se mais engajado com a organização. Pois o bem estar dos funcionários, acima de tudo, depende do bem estar da organização, pois empresa com- prometida é igual a funcionário motivado. Levando em consideração valores e transparências; princípios da gestão ambiental; gerenciamento dos impactos; educação ambiental; preservação da biodiversidade; relacionamento com os fornecedores; relacionamento com a sociedade $e$ compromisso social.

4. Incentivos de Longo Prazo: estabelecer um projeto de incentivo de longo prazo para as funções mais especificas da organização, como diretores, supervisores, coordenadores e outros. Através de um programa de remuneração que vincule sua permanência na empresa, não somente através de valores, mas também através da cota capital, ou seja, percentuais oferecidos para que o mesmo se sinta engajado com a organização.

5. Plano de Benefícios Flexíveis: programa de benefícios voltado à necessidade de cada grupo de funcionários, ou seja, específico conforme sua necessidade, , desde o oferecimento de lanches aos funcionários que estudam, até a resolução de problemas pessoais, financeiros e jurídicos, passando também pela isenção de descontos de encargos sociais.

6. Plano de Carreira: programa de benefícios voltado à necessidade de cada grupo, remunerar bem, acima da média do mercado. A política de remuneração é uma estratégia para ganhar visibilidade e atrair pessoas que desejam ter crescimento profissional em um ambiente saudável de trabalho. É importante haver uma diferenciação entre algumas funções, exemplo: para funções estratégicas utilizar o BSC (Balanced Scorecard), que na verdade é mensurado de maneira equilibrada sob as quatro perspectivas. Dessa forma contribui para que as empresas acompanhem o desempenho financeiro, monitorando, ao mesmo tempo, o progresso na construção de capacidades e na aquisição dos ativos intangíveis necessários para o crescimento futuro.

7. Programas de Recrutamento Interno: será utilizado um conjunto de técnicas e procedimentos visando atrair o candidato potencialmente 
qualificado e capaz de assumir determinado cargo na organização. Não haverá contratação de novos funcionários, sem antes haver uma consulta interna para o preenchimento da mesma, utilizando parâmetros adequados conforme perfil de cada cargo solicitado. O recrutamento será realizado através das necessidades presentes do setor de recursos humanos da empresa. Esse recrutamento requer um cuidadoso planejamento, que constitui uma sequência cuidadosa para contratação correta.

8. Programas de Treinamento e Desenvolvimento: o programa permitirá que o funcionário receba oportunidade de treinamento e desenvolvimento, estimulado e acompanhado pela sua liderança. O treinamento estará focado em desenvolver as qualidades, com o intuito de torná-los mais produtivos e desta forma contribuir para o alcance de seus objetivos dentro da organização. Tratando de um processo educacional de curto, médio ou longo prazo dependendo dos cursos escolhidos. O desenvolvimento será avaliado nas experiências do funcionário não necessariamente relacionadas ao cargo atual, mas que proporcionam oportunidade para desenvolvimento e crescimento profissional. Desta forma se avaliará separadamente tanto o treinamento quanto o desenvolvimento.

9. Programas de Participação Interna Através da Comunicação: este programa visará ouvir o funcionário, suas sugestões e reclamações, repassando o retorno após a conclusão das informações. As informações devem ser tratadas de maneira especial $e$ individual, sendo que o colaborador terá segurança com relação a questões éticas como de assédio moral, sexual, descriminações e outros. Deverá ser fornecida segurança total das informações e do indivíduo. Deverá se realizar um trabalho em conjunto com recursos humanos e liderança para uma maior abertura da comunicação, fazendo assim com que os colaboradores se exponham mais.

10. Programas de Auxílio a Famílias de Expatriados que Trabalham no Exterior: visa ao atendimento tanto aos colaboradores que atuam pela empresa fora do país, bem como para seus familiares que ficam no Brasil. Este programa deverá conter assistências médicas, hospitalares, psicológicas, educacionais, línguas, estudo da cultura do país, bem como seus costumes, direitos e deveres, repassado para expatriado $e$ familiares de forma a haver um consenso de esclarecimento deixando-os assim mais tranquilos sobre o assunto. Deverão ter um plano de ligações, repassado a ambos com horários, dias da semana e local. Se possível possibilitar aos familiares o uso da internet, para que os mesmos possam visualizar seus familiares fisicamente, para não haver nenhum constrangimento em sua chegada. Deixar claro quais serão suas atribuições no país, bem como local e data para ida e retorno. Tudo isto num pacote para que a família sinta segurança na empresa.

\section{REFERÊNCIAS}

ASSIS, Marcelino Tadeu. Indicadores de Gestão de Recursos Humanos. 1. ed. Rio de Janeiro: Editora Qualitymark, 2007

ALMEIDA, Walnice. Captação e Seleção de Talentos. 1. ed. São Paulo: Editora Atlas, 2008.

CHIAVENATO, Idalberto. A dinâmica do sucesso das organizações. São Paulo: Thomson, 2004.

CHIAVENATO, Idalberto. Administração teoria, processo e prática. 4. ed. Rio de Janeiro: Editora Campus, 2007.

DECENZO, David A; ROBBINS Stephen P. Administração de Recursos humanos. Rio de Janeiro: LTC Editora, 2001.

EDVINSSON, Leif \& MALONE, Michael S.: Capital intelectual. São Paulo: Makron, 1998

GASALLA, José Maria. A nova Gestão de Pessoas - o talento executivo. 8. ed. São Paulo: Editora Saraiva, 2007.

GIL, Antonio Carlos. Gestão de Pessoas - enfoque nos papéis profissionais. 7. ed. São Paulo: Editora Atlas, 2007.

KANAANE, Roberto. Comportamento Humano nas Organizações - O homem Rumo ao século XXI. 2. ed. São Paulo: Editora Atlas, 2008. 
LACOMBE Francisco; HEILBORN, Gilberto. Administração - Princípios e Tendências. 1. ed. São Paulo: Editora Saraiva, 2003.

MARRAS, Jean Pierre. Gestão de pessoas em empresas inovadoras. São Paulo: Futura, 2005.

NONAKA, Ikujiro e TAKEUCHI, Hirotaka. Criação do Conhecimento na Empresa: como as empresas geram a dinâmica da inovação. Rio de Janeiro: Campus,1997.

ROOS, J. et al. Intellectual Capital. London: Macmillan Business, 1997.

STEWART, Thomas A. Capital Intelectual: a nova vantagem competitiva das empresas. 2. ed. Rio de Janeiro: Campus, 1998.

O capital intelectual dosa talentos. Jornal do Comércio, Porto Alegre, 16 jul. 2007.

Maiores e Melhores 2012. Revista Exame - Edição Especial. Set 2008

As pessoas no balanço. Revista Melhor Gestão de Pessoas, ago. 2007.

O que mais pode ter?. Revista Melhor Gestão de Pessoas, jul 2008

A estratégia pelo trabalho. Revista Melhor Gestão de Pessoas, abril 2008.

A vez do Capital Intelectual. JC Empresas \& Negócios, abril 2008 .

Entrevista a Ralph Stacey. Disponível em: $h t t p: / / w w w . j a n e-$ lanaweb.com/digitais/stacey.html. Acesso em: 20/05/2008

Recebido em: 20/out/2011

Aceito em: 26/nov./2011 